\title{
A Comuna de Paris de 1871: análise conceptual e recepção em Portugal
}

\author{
The Paris Commune of 1871: conceptual and reception analysis \\ in Portugal
}

Tiago Rego Ramalho Doutorando em História Contemporânea (FCSH-UNL) Investigador Integrado do Instituto de História Contemporânea (FCSH-UNL) tiago_rego_ramalho@hotmail.com

\begin{abstract}
Resumo: A Comuna de Paris de 1871 representou, no quadro da segunda metade do século XIX, um evento significativo em vários âmbitos. Assinalando-se como um momento histórico original e amplamente noticiado, pretende-se discorrer em torno de um conjunto de problemáticas que visam demonstrar a particular relevância deste acontecimento, desde logo pela sucessão de ocorrências, pela atuação dos seus protagonistas ou, ainda, pelo impacto internacional do mesmo. Deste modo, importa considerar o seguinte: realizar um levantamento da produção teórica, no intuito de analisarmos o conceito de revolução, procurando perceber em que medida a mesma é considerada por diferentes enquadramentos teóricos, qual a sua relação com outros conceitos ou quais as características que a definem por excelência; num segundo momento, e no quadro de uma contextualização que verse sobre a Comuna de Paris de 1871, pretende-se aferir das possibilidade da mesma ser retratada enquanto revolução e apresentaremos os contornos da sua receção em Portugal.
\end{abstract}

Palavras-Chave: Revolta. Revolução. Movimento operário. Imprensa. Século XIX.

Resume: The Paris Commune of 1871 represented, during the second half of the nineteenth century, a significant event in various ways. As a unique historical moment and widely reported, we intend to discuss a set of issues to demonstrate the particular importance of this event, from the series of occurrences, the actions of the protagonists or even the international impact of it. It is therefore important to consider the following: to conduct a survey of theoretical work in order to analyze the concept of revolution, trying to understand to what extent it is considered by different paradigms, what its relationship with other concepts is, or what characteristics define it par excellence; subsequently, and within a context that addresses the Paris Commune of 1871 , it is intended to assess the possibility of it being portrayed as a revolution and to present the outlines of its reception in Portugal.

Key-words: Revolt. Revolution. Press. Labor movement. XIX century.

Originais recebidos em: 05/01/2016

Aceito para publicação em:24/06/2016

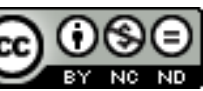
Comercial-Vedada a criação de obras derivadas 3.0 Unported License. 


\section{Introdução}

"A verdadeira revolução acontece quando mudam os papéis e não apenas os autores."

(Gilbert Cesbron)

No respeitante à estrutura, esta investigação pretende enveredar sobre dois planos. Se por um lado, pretende-se apresentar uma dimensão teórica, a dimensão prática não sairá menosprezada, pela necessária conexão que deve existir entre os dois planos. Num primeiro capítulo, perspetiva-se uma abordagem histórica e metodológica sobre o conceito de Revolução, desde a sua evolução num determinado espaço cronológico, tal como um conjunto de ideias que passaram a coexistir com a mesma. A interpretação do conceito pelas várias escolas de pensamento e figuras que se debruçaram sobre o mesmo não deixa de ter pertinência para possíveis classificações. Cabe-nos descortinar as potencialidades da terminologia revolucionária, aferindo se as mesmas devem ser analisadas sob um prisma rigoroso e ou maleável.

Isto é, a tipologia deve ser rígida e constituir-se por uma panóplia de ideias fixas, transversais e imutáveis; ou, por sua vez, cabe-lhe atribuir a si mesmo uma flexibilidade na análise das ocorrências históricas, assumindo assim um grau de praticabilidade? Prosseguindo no plano teórico, uma clarificação de conceitos deve ser produzida sob forma de evitar excessivas banalizações e confusões conceptuais. Atendendo sempre a resultados práticos produzidos pela História, devemos aferir sobre casos concretos em coexistências ou não de práticas semelhantes entre conceitos como Revolução, Revolta, Rebelião ou Golpe de Estado. Certamente que os pontos de contacto surgem, embora seja manifesto que as dissemelhanças devam ser extraídas param uma compreensão mais rigorosa dos efeitos produzidos pelos mesmos.

Sendo que prática e teoria devem coabitar e surgem infinitamente conectadas, importa aplicar a doutrina terminológica a um caso muito concreto, como foi o da Comuna de Paris de 1871. Passando brevemente pelos contornos socioeconómicos e políticos que se produziram na Comuna pela via de reformas profundas e inovadores, importa essencialmente esclarecer o uso do termo aplicado ao caso em estudo, tal como evidenciar se a Comuna é uma Revolução ou se não passa de uma mera insurreição levada a cabo por revoltosos, culminando e findando por um ideal de mera Revolta. Um último capitulo da investigação, centrar-se-á na receção que se produziu em Portugal da 
Comuna de Paris de 1871, quer seja por uma imprensa ou pelo debates parlamentares produzidos. A pertinência de um receção vista através dos Debates Parlamentares, justifica-se pela escassa ou mesmo nula produção historiográfica existente, visto que a predominância do trabalho realizado reside em órgãos de imprensa, meios culturais ou académicos.

\section{Uma Ideia de Revolução}

Revolução, do latim Revolutio, Revolutus, do particípio passado Revolvere ${ }^{1}$, é uma expressão que tem sofrido alterações históricas, desde logo se partirmos de uma análise etimológica do termo. Vejamos o desenvolvimento histórico que se abateu sobre o mesmo e quais as hermenêuticas sofridas. Com o advento da Revolução Francesa, a expressão "Revolução", granjeará um novo sentido e uma nova dimensão, devido à entrada em cena do conceito de liberdade (DUSO, 2005, p. 209) que se assumirá como eixo central nos desenvolvimentos revolucionários. Digamos que este momento histórico celebra a perda do anterior significado, «moto circular que volta a si mesmo», para lhe conferir um novo conteúdo. A Revolução, em si mesmo, passa a ser compreendida à luz da novidade, ou seja, relaciona-se com o estabelecimento de uma nova ordem. O final do século XVIII, assinalado pela Revolução Francesa, identifica a mudança de sentido que se abaterá sobre as Revoluções.

Doravante, a Revolução perde o seu significado e a sua ligação à ideia de Retorno ou Regressão, passando a reconhecer-se sob o prisma da Evolução/Mudança ou Emancipação. Podemos afirmar que nos deparamos com uma linearidade incorporada no novo sentido revolucionário, ao invés de uma circularidade que se manifestava na anterior conceptualização. Como se referiu acima, a Revolução passa a ser compreendida sob o signo da Liberdade: «A Revolução é o processo de libertação das amarras do poder existente e da cristalização dos diversos direitos e privilégios» (DUSO, 2005, p. 209). Consequentemente, a liberdade permite uma libertação com o passado, possibilitando uma edificação de um novo regime ou ordem política. Destarte, ela assegura e garante a mudança, o rompimento com o velho, apesar de não introduzir

\footnotetext{
${ }^{1} \mathrm{Http}: / /$ www.gramatica.net.br/origem-das-palavras/etimologia-de-revolucao/ [Consultado a 15/01/2014].
} 
necessariamente, uma valoração que só poderá acontecer ou não, dependendo das circunstâncias posteriores.

As Revoluções devem ser analisadas para além das simples mutações que operam e como tal, a problemática do começo das mesmas é indissociável, mas não exclusivo, na interpretação das Revoluções. A Idade Moderna é o marco histórico em que as questões sociais passam a ser equacionadas na esteira da Revolução. A secularização, o nascimento de um campo secular, torna-se um fator pertinente para o fenómeno da Revolução (ARENDT, 1971, p. 25). Para Hannah Arendt, em todas as Revoluções elementos como a novidade ou singularidade desempenham um papel efetivo, depositando na ideia de Liberdade a chave para se entender as revoluções na Idade Moderna. Assim, "só podemos falar de revolução quando esta característica de novidade está presente e quando a novidade se liga à ideia de liberdade" (ARENDT, 1971, p. 33). Uma qualquer Revolução, enquanto processo dialéctico, deve compreender-se sob o signo da mudança, do começo e da própria violência, em que cada momento define-se entre as múltiplas etapas que emergem na Revolução.

Ainda no Século XVII, a Revolução surgirá associada à sua forma original, entendida por intermédio da repetição, enquanto momento cíclico. Este contexto sóciopolítico em que se insere um entendimento revolucionário ainda comporta uma aversão à novidade e violência, imbuído por um carácter conservador e de restauração. Se a Glorious Revolution (1688) havia comportado um carácter conservador, não alterando a estrutura organizativa da sociedade de forma substancial e por isso, conectada com o sentido primário do termo Revolução, a Révolution Française por sua vez, sinaliza uma nova compreensão do termo: «A partir da Revolução Francesa, passou a ser comum interpretar toda a sublevação violenta, fosse ela revolucionária ou contra-revolucionária, em termos de uma continuação do movimento originariamente começado em 1789» (ARENDT, 1971, p. 49). Com o Século XIX, nasce uma dimensão de unicidade alicerçada ao fenómeno da Revolução: Révolution en Permanence. Esta disposição cunhada no seio da Revolução Francesa irá influenciar toda uma escola marxista, devedora desta modalidade Revolucionária.

A radicalização como fator característico das Revoluções pode-se afirmar nas etapas que marcam uma dada Revolução. Segundo a lógica de Crane Brinton (GASPAR, 2003, p. 3-4), as condições iniciais que propiciam o deflagrar de um 
turbilhão revolucionário podem ser encontradas na crise de legitimidade, na fragmentação das classes dirigentes ou numa perda de autoridade, celebrando-se uma transição, em que os revolucionários despossam o antigo regime. A génese da Revolução Moderna passa por recomeço histórico, sedimentando-se pela via da institucionalização de um novo regime político. No respeitante à classificação e elaboração de tipologias conformes às Revoluções, a multiplicidade de visões impera. Desde logo, «As revoluções podem distinguir-se pelas suas raízes políticas: a americana escapa ao terror e ao despotismo democrático por ser a única que não decorre de um regime autocrático, como a francesa, a russa ou a chinesa»(GASPAR, 2013, p. 4). Continuando pela caracterização das Revoluções, podemos fazer uma distinção entre revoluções burguesas do século XVIII e revoluções proletárias do século XIX, tal como revoluções autoritárias e totalitárias das revoluções liberais. Uma outra visão anatómica das Revoluções leva-nos a conceber revolução que são concebidas de baixo para cima, tal como revoluções de cima para baixo ${ }^{2}$. Uma outra divisão é protagonizada por revoluções limitadas e revoluções permanentes, em que as primeiras, pela encurtada dimensão temporal, formalizam e institucionalizam um novo regime político; as últimas abarcam uma longa extensão no tempo, perdurando o movimento revolucionário.

Segundo Charles Tilly,

Seja o que for que envolvam as revoluções incluem sempre transferências forçadas de poder entre os Estados; e que, portanto, qualquer descrição útil das revoluções deve ter em conta, entre outras coisas, o modo como os Estados e o uso da força variam no tempo, no espaço e no cenário social (TILLY, 1996, p. 26).

$\mathrm{Na}$ perspetiva adotada pelo autor, as circunstâncias envolventes, ou seja, determinadas condicionantes causais como são o tempo ou espaço, assumem-se como determinantes para a explicação de cada Revolução, refutando qualquer tendência explicativa que recai sobre leis próprias que fundamentam a Revolução. Mostrando-se cético a qualquer modelo único e unificador por forma a explicar as Revoluções, visto que nos surge sempre um caso concreto que se ausenta da regra prescrita, defende uma explicação pluralista no tocante às causas das mesmas. Apesar de recusar um carácter unitário na explicação das causas para as Revoluções, no que toca ao tempo e espaço, torna-se possível descrever mecanismos causais idênticos para uma vasta panóplia de

\footnotetext{
${ }^{2}$ As primeiras (de baixo para cima) são assinaladas pelas massas efervescentes, sendo que as últimas (de cima para baixo) demonstram-se por uma violência estatal.
} 
situações revolucionárias, como por exemplo, «a constatação de que um Estado tido como poderoso é de facto vulnerável ou a dissolução parcial dos poderes do Estado que muitas vezes se verifica a seguir às guerras» (TILLY, 1996, p. 29).

As Revoluções, segundo Tilly, abarcam duas componentes: as situações revolucionárias e os resultados revolucionários. No que respeita às situações revolucionárias, as revoluções de maior grandeza comportam sempre uma sucessão das mesmas, em que se alteram por exemplo, os contestatários do poder, os governantes ou as reivindicações. Na maioria dos casos, as situações revolucionárias não desembocam em resultados revolucionários, ou seja, «Tem-se um resultado revolucionário quando ocorre uma transferência do poder do Estado daqueles que o detinham no início da situação de múltipla soberania para uma nova coligação governamental» (TILLY, 1996, p. 36).

Aquilo que move uma qualquer Revolução, ou seja, o eixo central de uma qualquer agitação revolucionária é alvo de disputa, essencialmente por duas escolas de pensamento. Por um lado, uma conceção idealista ${ }^{3}$ da Revolução tende a depositar na Ideia a força motriz de toda o processo revolucionário. Assim, as Ideias determinam os acontecimentos revolucionários, justificando-os à luz de um determinado pensamento, sendo que as condições materiais refletem-se numa fase posterior, sendo devedoras das Ideias. Uma outra visão tende a conceber as Revoluções como o reflexo de determinados fatores visíveis na Sociedade, ou seja, as condições materiais envolventes, condicionando as populações, criam os elementos propícios a essas transições históricas exercidas por intermédio das Revoluções.

\section{Clarificações Conceptuais}

Importa também clarificar entre si, conceitos como Golpe de Estado, Revolução, Revolta ou Rebelião. A existência de pontos de contactos é manifesta, embora as diferenças sejam relevantes para a investigação. Existe uma tradição marxista, em autores como Engels ou Trotsky, que relataram a conquista do estado sob um ponto de vista técnico. Assim, Trotsky considerava a insurreição como uma arte, tal como perfilhará o próprio Engels, defendendo a existência de um conjunto de regras e

\footnotetext{
${ }^{3}$ Dentre dos seguidores desta perspetiva liberal encontra-se um destacado teórico da Revolução Francesa, François Furet.
} 
procedimentos alicerçados a esta prática, manifestada por um imenso calculismo, como foi exemplo a própria Revolução de Outubro de 1917. O próprio Cúrzio Malaparte, autor da Ténica del copo di stato, afirmará que a conquista e defesa do Estado devem ser entendidas como um problema técnico e não político, ou seja, as circunstâncias que possibilitam a ocorrência de um golpe de estado não são necessariamente de natureza política e social e não dependem das condições gerais do país (MALAPARTE, 1984, p. 163). Desta forma, o exemplo soviético, na sequência do que se vem proclamando, pode ser descrito da seguinte forma: «O golpe de Estado foi o momento militar da insurreição, dentro de um processo revolucionário em curso havia vários meses. Golpe de Estado e Revolução são dois acontecimentos distintos, porém não se excluem e por vezes, completam-se, como ocorreu na Rússia em 1917» (BANDIERA, 2009, p. 70).

Segundo Hannah Arendt (ARENDT, 1971, p. 39), acontecimentos como Rebeliões ou Revoltas ficam aquém das Revolução no respeitante aos resultados ou consequências produzias. A Revolução incorpora um sentido de libertação que não transparece na Revolta ou Rebelião, tal como na edificação de uma liberdade renovada. Num esclarecimento sobre os termos "Revolução" e "Golpe de Estado", podemos afirmar que a primeira passa por derrubar a estrutura económica e social de uma dada sociedade, sendo que o último implica, na maioria das vezes, uma preservação do status quo ou simplesmente por alterar um governo ou ordenamento jurídico, derrogando ou reformando a Constituição. Esta distinção acentua o carácter disjuntivo dos mesmos, ao invés da conjunção anteriormente identificada, «as revoluções são mais que insurreições bem-sucedidas e não temos o direito de chamar revolução a qualquer golpe de estado ou até de vermos uma revolução em cada guerra civil» (ARENDT, 1971, p. 34). Ainda no tocante às características que podemos associar ao golpe de estado, convém ressalvar o papel determinante de uma elite constituída e determinada a realizar o mesmo, a aplicação de uma violência controlada, uma rapidez no processo de tomada do poder e o pouco impacto que o dado golpe produzirá sobre a estrutura económica e social, sendo este último fator determinante para se demarcar um terreno entre Golpes de Estado e Revolução, sem nunca se negligenciar os terrenos comuns a ambos os procedimentos.

Umberto Melotti, na obra Revoluzione e Società, desenvolve uma tipologia de Golpes de Estado, sendo que o momento revolucionário surge associado a um dos modelos desenvolvidos, levando-nos a afirmar que a esfera estatal é o elemento decisivo 
em todos as modalidades. Basicamente, o autor no exercício realizado, somente concebe o momento revolucionário numa associação direta com o Estado. Assim, dentre os três modelos teorizados (BANDIERA, 2009, p. 72), deparamo-nos com (1) o golpe de estado revolucionário, cujo objetivo passa por transformar a estrutura económica e social; (2) o golpe de estado reformista, que visa promover determinadas mudanças políticas, embora não pretendendo alterar os fundamentos da Sociedade; por fim, (3) o golpe de estado governamental, visando o reforço do poder político, já consolidado pelos seus detentores. Por todo este imaginário conceptual, entende-se a necessidade de aclarar as semelhanças e dissemelhanças entre práticas, partindo da noção de Revolução e relacionando-as entre si.

\section{A Comuna de Paris de 1871: Uma Revolução?}

Nesta fase, importa materializar os ensinamentos teóricos, ou seja, aplicá-los e verificá-los consoante a praxis histórica. O caso histórico concreto a que nos propormos interrogar sobre a sua potencial dimensão revolucionária ou ao invés, somente uma tentativa fracassada, trata-se da Comuna de Paris de 1871. Para averiguar as suas repercussões e a existência ou não de Revolução, importa-nos ater sobre alguns factos históricos e descrever o contexto socio-económico e político em que se deram estes acontecimentos. A Comuna de Paris de 1871, tendo sido um acontecimento com forte impacto, mas ao mesmo tempo também fugaz pela escassez da sua duração (apenas 72 dias), não capitulou como uma efemeridade histórica. Todo o «Mundo Marxista» não esqueceria a relevância do mesmo para aquilo que podemos designar por uma «história global do movimento proletário internacional».

Segundo as palavras de Alfred Manfred, «Até à revolução de 1905 na Rússia e de certo modo, até à Grande Revolução Socialista de Outubro, a Comuna de Paris foi o expoente máximo do movimento revolucionário proletário mundial» (LÉNINE, 1975, pp. 11-12). Na continuação desta exposição, verificaremos se perfilhamos da integralidade deste argumento. Este evento histórico, representativo de um movimento de massas, verifica-se em algumas medidas de cariz político: (1) Abolição do Exército Permanente; (2) Abolição da Burocracia; (3) Separação da Igreja e do Estado e (4) Instituição do ensino gratuito; tal como em determinadas medidas económicas, como 
foram exemplo as proibições do trabalho noturno dos padeiros ou as proibições das multas.

No respeitante às causas que possibilitarem a existência da Comuna, dentre muitas que podem ser apontadas, identificamos a existência de um forte movimento operário, possibilitado pelo desenvolvimento industrial, sendo que começava a estreitar laços com a I Internacional; Patriotismo denegrido, necessitando de ser reabilitado, devido ao cerco de Paris por parte dos Prussianos; sobressalto republicano. Ainda nas fragilidades que a França vivia nas vésperas da Comuna, refira-se que nos anos de 1866/1867, a economia francesa passava por uma crise profunda, tendo como consequências, a ruina de bancos e empresas relevantes, verificando-se um agravamento da miséria entre o proletariado, sendo que a pequena-burguesia também surgia fragilizada. Reforçando o argumento anterior, o pendor operário que se vislumbrou na Comuna havia sido inquestionável, visto que entre os combatentes, $84 \%$ dos "Communards" presos são trabalhadores manuais, sendo que a participação operária no Conselho Geral da Comuna representa cerca de $30 \%$, ou seja, afigura-se como um resultado único na história francesa. As reformas realizadas na legislação social, tal como as pressões e estímulos que vinham do exterior, também se afiguraram como fatores relevantes para evidenciar o carácter fortemente operária que cobria a Comuna.

Essas pressões que provinham do exterior verificavam-se sobre o Conselho Geral, que estava sujeito a uma forte pressão externa que provinha de sindicatos, das associações de trabalhadores, dos jornais ou mesmo das secções da I Internacional. O efeito democratizador também se abateu sobre o ensino, surgindo assim uma reforma da escola laica, gratuita e obrigatória. Dentre as reformas políticas, a Democracia Direta passa a ser uma realidade, numa lógica de inclusão de todos, ou seja, todos os habitantes da Comuna passam a poder ter um papel ativo na administração e na tomada de decisão, corroborando com ideias como a iniciativa popular ou o autogoverno. Com esta instauração, as mulheres ${ }^{4}$ surgem como elemento crucial nesta ótica de participação política. Destaca-se também, pela primeira vez na história mundial, o papel que a Comuna confiou a estrangeiros, na administração de importantes postos dirigentes. Embora a Comuna tenha tido na pessoa do operariado o principal suporte na edificação

\footnotetext{
${ }^{4}$ As mulheres desempenham um papel relevante em vários planos de ação, inclusive em levantamentos populares, destacando-se a figura de Louise Michel.
} 
da mesma, este papel também haveria de ser compartilhado com a pequena burguesia, verificando-se assim uma aliança $^{5}$ entre trabalhadores e pequeno-burgueses, destacando-se aqui a relevância dos intelectuais. No campo das ideias políticas, as escolas de pensamento que mais se afirmaram no seio da Comuna foram $o$ Proudhonismo, o Blanquismo e o próprio Marxismo ${ }^{6}$.

Após a contextualização histórica da Comuna de Paris de 1871, levando-nos a descrever causas, desenvolvimentos e impactos posteriores, cabe-nos por fim, apontar se estes desenvolvimentos são suficientes para serem abordados enquanto uma Revolução em si, ou seja, será que faz sentido considerar a Comuna de Paris de 1871 como uma Revolução? A nossa visão, secundado pelas tipologias anteriormente descritas, leva-nos a crer que este acontecimento histórico não é passível de ser considerado como uma Revolução, desde logo pela dimensão temporal. Assim, os meros dois meses de existência da Comuna não nos permitem apurar o grau de fiabilidade no tocante a presumíveis transferências de Poder.

Seguindo a visão de Tilly (TILLY, 1996, p. 37), vislumbramos que são raras as situações revolucionárias que desembocam em resultados revolucionários. Para este, guerras civis ou lutas de sucessão podem ser interpretadas como autênticas Revoluções, na medida em que o Poder surja com novos detentores na sequência de uma cisão forçada da soberania. Assim «As Revoluções inglesas de 1640-60 e 1687-89 entram claramente nessa categoria, se bem que a derrotada Comuna de Paris de 1871, que não chegou a provocar uma transferência duradoura de poder, já não esteja nessas condições» (TILLY, 1996, p. 37).

Assim, podemos afirmar que a Comuna ficou-se pela mera insurreição revolucionária, não podendo constituir-se como Revolução, no sentido amplo do termo tal como tem vindo a ser trabalhado, devido às contrariedades verificadas no cenário espacial e temporal. Segundo os ensinamentos adotados, o sentido de libertação ancorado num firmamento da Liberdade, como força motriz da Revolução, não se efetivou plenamente no decurso deste momento histórico. Se a Comuna não pode ser

\footnotetext{
${ }^{5}$ De referir que os franco-mações também se afirmaram como apoiantes da Comuna, participando na construção da mesma.

${ }^{6}$ Apenas com a I Internacional (1864) o Marxismo começou a ganhar uma dimensão de relevo, sendo que as ideias dificilmente penetravam entre os meios desfavorecidos parisienses, pela forte repressão que se verificava. Como tal, dentre as três correntes, o Marxismo surgia como a mais frágil e menos disseminada.
} 
caracterizada como Revolução, defendo que este marco histórico do Século XIX pode e deve ser aflorado em descrições úteis sobre as Revoluções Contemporâneas, pelo legado e simbologia que haveria de transmitir.

\section{A Receção da Comuna de Paris de 1871 em Portugal}

Importa aqui determo-nos sobre os impactos da Comuna de Paris em Portugal, ou seja, demonstrar o seu legado, tal como apresentar os domínios onde se fez sentir com maior vivacidade ou ainda, abordar casos individuais que se tenham afirmado pelas projeções da Comuna. Desde já, convém salientar o forte impacto que a Comuna imprimiu sobre uma determinada camada de jovens intelectuais, em especial a juventude académica de Coimbra, que se fazia representar pela chamada "Geração de Setenta". Neste clube académico, figuram nomes como Antero de Quental, Eça de Queiroz $^{7}$, Teófilo Braga, Augusto Soromenho ou Oliveira Martins. As realizações da Comuna propiciariam, em Portugal, a um florescimento do ideário marxista, tal como da AIT (Associação Internacional do Trabalhadores), sendo mesmo formada, em Agosto de 1871, uma secção da mesma. Por aqui, vê-se que as sementes da Comuna estavam a ser lançadas ao Mundo. No tocante às figuras que marcaram os desenvolvimentos parisienses, os chamados "Communards", refira-se que em momentos posteriores à derrota que se verificou nesses intentos revolucionários, personalidades como Paul Lafargue, Lucien Combatz ou Alfredo Fillon deslocar-se-iam a Portugal, confraternizando com apoiantes portugueses, partilhando ideias e experiências. Retratando a imprensa Coimbrense,

O Tribuno Popular apresenta um virulento e sectário ódio contra a Comuna [...] Se o Conimbricense não deixava de informar algumas das medidas tomadas pelos revolucionários parisienses, escapando todavia muitas das de maior relevância social e democrática, A Federação chegou a publicar a proclamação datada de 19/04/1871, em que a própria Comuna denunciava as calúnias de Versailles e esclarecia com pormenor os seus objetivos programáticos (VILAÇA, 2005, p. 31).

Esta última publicação, A Federação, apresenta-se como compreensiva, revendo-se de algum modo na ações perpetradas pela Comuna, alegando que os

\footnotetext{
${ }^{7}$ Havia sido neste período que Antero de Quental elaborando o ensaio "O que é a Internacional?", tal como Eça de Queiroz, por via do seu "Crime do Padre Amaro", fazem manifestar as influências provindas da Comuna de Paris de 1871.
} 
excessos seriam transversais a todas as Revoluções. A violência é assim assumida como fator preponderante nas Revoluções Modernas, embora pese aqui uma certa banalização do termo "Revolução". Também na cidade de Coimbra, dar-se-ia aquela que se afirmava como a primeira e mais enérgica defesa da Comuna. Assim, José Falcão publicaria em folheto impresso um panfleto intitulado A Comuna de Paris e o Governo de Versailles, Apesar do anonimato da publicação, visto que José Falcão temia futuras retaliações, a autoria do escrito viria a público, tendo desencadeado um processo judicial, a 18/07/1871, com variadíssimas ocorrências (VILAÇA, 2005, p. 51). Desde logo, a publicação e posterior censura que mereceu este escrito foram alvo de debates parlamentares na Câmara dos Senhores Deputados da Nação Portugueza, onde a oposição, pela figura de Mariano de Carvalho, interpelaria o Presidente do Conselho de Ministros sobre uma notícia que circulava dando conta da proibição da venda do livro supracitado pelas autoridades competentes. Apesar de discordar dos acontecimentos que ocorreram na Comuna, acusa-se este tipo de práticas de serem antiliberais e absurdas. Acrescido a isto, «A auctoridade mandou prohibir a publicação do livro do dr. Falcão, mas não consta que tenha sido prohibida a venda de livros que têem vindo de França defendendo a comuna» ${ }^{8}$. Respondendo o Senhor Presidente do Conselho de Ministros às questões sobre esta situação de proibição de venda do opúsculo e quais os motivos que foram levados em conta para que a interdição fosse efetivada, alegou que os estabelecimentos do Estado não poderiam permitir a divulgação de ideários como aqueles que são manifestos no referido documento. Como tal, alegando que a imprensa da Universidade fazia parte do Estado, local onde a publicação se tinha dado, achou por bem censurar o diretor dessa imprensa ${ }^{9}$. Entre a proibição da impressão da obra e a proibição da venda da obra, a querela parlamentar tinha-se instalado. Esta publicação ainda voltaria a ser mencionada no hemiciclo ${ }^{10}$.

Seria na manhã do dia 20 de Março, que a população de Lisboa seria alertada para as ocorrências insurrecionais que deflagravam na cidade de Paris, dominando um sentimento de pasmo e receio. Deste modo, seguindo o relato do Jornal do Comércio no

\footnotetext{
${ }^{8}$ Diário da Câmara dos Senhores Deputados da Nação Portugueza, 11 de Agosto de 1871, Ata ${ }^{\circ} 70$, p.188.

${ }^{9}$ Cf. Diário da Câmara dos Senhores Deputados da Nação Portugueza, 11 de Agosto de 1871, Ata nº70, p.188.

${ }^{10}$ Diário da Câmara dos Senhores Deputados da Nação Portugueza, 5 de Setembro de 1871, Ata no87, p.738.
} 
dia 21 de Março, «Cumpre dar remédio eficaz e castigo exemplaríssimo. Não pode tolerar-se que a sorte de um povo dependa de uns garotos que vivem só da anarquia e do saque» (ALVES, 1971 p. 38). Por este relato dos acontecimentos, torna-se notário o descrédito que esta publicação enfatiza no respeitante aos acontecimentos, reduzindo-os atos que colocam o todo, neste caso a Nação Francesa, em causa. Para além do Jornal do Comércio, a Imprensa Monárquica tem nas visões de publicações como foram $A$ Gazeta do Povo ou a Revolução de Setembro, um sentimento nefasto perante o sucedido, defendo a necessidade imperiosa de se evitar uma guerra civil e consequentemente, reprimir a revolta e os revoltosos. Constata-se uma preocupação com a integralidade da Nação, desprestigiando-se ações que podem desembocar numa guerra civil, para além do cuidado que esta Imprensa tem em catalogizar as ocorrências, renunciando a banalizações recorrentes.

Perante uma Imprensa marcadamente conservadora como foi a Imprensa Clerical, publicações como A Nação ou o Bem retratam os agitadores políticos, envolvidos na Comuna, como um conjunto de assassinos, aduladores ou ladrões. O próprio Papa Pio IX apresenta referências aos revoltosos bastante desagradáveis, tratando-os como um bando de homens ferozes e perversos (ALVES, 1971 p. 42). Na visão da Imprensa Regeneradora, a Correspondência de Portugal, no dia 24 de Março, afirmava: «São deploráveis as notícias que nos chegam de Paris. Impera a anarquia por toda a parte. O poder está nas mãos dos vermelhos mais exaltados» (ALVES, 1971, p. 43). Entre as publicações conotadas com a Direita Portuguesa, clarificam-se e distinguem-se os perigos da Anarquia e do Socialismo, ou seja, as modalidades que participação política que surgiriam na Comuna eram vistas como nefastas, acarretando prejuízos para o Poder Estatal, num claro receio de que o mesmo pudesse cair na rua, ficando desamparado. Continuando pelas publicações de cariz monárquica, embora reformistas, o Diário Popular não se apresentava crítico da Comuna, tal qual os periódicos anteriormente referidos.

Ressalve-se que a população portuguesa acabava por discutir a Comuna e os seus acontecimentos na rua, em locais de venda de jornais e de afixação de telegramas ou nos intervalos de espetáculos. Assim, os seus desenvolvimentos passam a estar na ordem do dia, levando a que sejam tema de conversa nas discussões diárias ou nas leituras realizadas. Paris passa a granjear o epíteto de cidade Revolucionária, por 
excelência, sendo inseparável das conversações conducentes com a Comuna. Prosseguindo por uma análise na receção, por parte da Imprensa Monárquica, que se verificou sobre os Decretos da Comuna, como por exemplo a abolição do trabalho noturno das padarias, tendo sido retratado pelo Jornal do Comércio e pela Revolução de Setembro, no dia 29 de Abril, dos seguintes modos: «A Comuna suprimiu, a pedido dos amassadores de padeiro, o trabalho noturno. Deste modo se veem os habitantes de Paris obrigados a comer pão duro» (ALVES, 1971, p. 50).

A 5 de Maio, perante as últimas incidências da Comuna, o jornal $O$ Viriato, declara que: «Lá dentro, dominando Paris a Comuna, nefanda, abominável, execranda, ímpia, vergonhosa; cá fora em Versailles dirigindo o cerco Thiers, o político profundo, o diplomata insigne, o historiador abalizado, o publicista ínclito, o pacificador, o verdadeiro elemento da ordem»(ALVES, 1971, p. 67). A generalidade da Imprensa, conservadora perante os intentos da Comuna, acaba por criar uma autêntica campanha de atemorização da sociedade civil. A Comuna surge fortemente associada a uma guerra civil como resultado inevitável de um liberalismo excessivo. Assim, pretende-se influir na opinião pública ideias que vão no sentido de apoiar uma determinada constituição, que possa funcionar como salvaguarda de um governo de linha política mais dura.

Na Imprensa republicana, o Apóstolo da Verdade tratará a Comuna como «Uma horda de assassinos arvorou-se como o título de "Comité" Central Republicano, hasteando a bandeira vermelha. O assassínio é a ordem do dia» (ALVES, 1971, p. 131). A República Federal, com localização em Lisboa e considerado como a publicação republicana com maior projeção, retrata a Comuna como uma revolução triunfante e desde logo, podemos contrastar com uma Imprensa que não depositava na Comuna grandes expectativas e muito menos, retratando-o como uma Revolução vitoriosa. Seguindo as terminologias e tipologias estudadas, uma Imprensa dita mais vanguardista, associada ao republicanismo e ao socialismo, tende a retratar a Comuna como uma Revolução Proletária, antecipando-se desde logo a um século XX que deterá por excelência uma vasta panóplia de Revoluções que poderemos designar como Proletárias e que ao mesmo tempo, se encaixam no perfil de Revolução realizadas de baixo para cima. Terminando com a Imprensa Socialista, publicações como foram $O$ Defensor do Operário ou O Protesto Operário, afirmaram-se importantes veículos de transmissão do ideário e das realizações da Comuna, entre os meios operários portugueses. 


\section{Conclusão}

Findada esta investigação, cabe-me renovar a defesa de uma posição conciliadora entre vertentes teórico-práticas. Fica claro pelo escrutínio da terminologia estudada, a rigorosidade a exigência que devem ser depositadas na aplicação dos termos a casos concretos. Para além do mais, a pluralidade e flexibilidade devem estar comportadas na aferição de casos históricos, sob o erro de produzirmos uma tipologia para cada situação revolucionária. A dimensão espacial, tal como a dimensão temporal, comportam índices de incerteza e novidade, obstruindo uma certa regularidade, levando-nos a recusar tipologias ou classificações demasiado rígidas. No tocante ao caso histórico em estudo, a Comuna de Paris de 1871, sendo raramente ou quase nunca integrada em estudos teóricos que incidem na conceptualização da Revolução, a análise que se produziu que a mesma não se efetivou como resultado revolucionário, ficando-se por uma mera situação revolucionária. A curta duração dos acontecimentos apresenta-se como o argumento mais eficaz e notório para demonstrar o sentido de Revolta que existiu na Comuna, nunca se concretizando numa Revolução Moderna, embora pese os contributos que transmitiria para as vanguardas revolucionárias do século $\mathrm{XX}$, sustentadas pelo impacto que os desenvolvimentos da Comuna produziram entre os meios proletários. Porventura não será excessivo argumentar que as funções sociais que hoje reconhecemos à esfera estatal se assumam como um legado da Comuna de Paris.

O outro lado da investigação, ou seja, a receção que a Comuna granjeou entre os meios portugueses, destaca-se o enorme impacto que a mesma deteve sobre uma certa elite intelectual coimbrense, que se afirmaria no mundo das letras e no mundo político, em especial a oposição republicana que se viria a desencadear. Se uma imprensa de cariz monárquico, mas também alguma conservadora e clerical, abominou as realizações da Comuna, vulgarizando as figuras como um bando de revoltosos que pretendiam retirar a ordem à vida pública francesa, por outro lado, a imprensa republicana e socialista depositava na Comuna uma esperança de progresso social. Estes últimos retratavam a Comuna como uma Revolução conduzida por revolucionários, embora os primeiros continham-se na aplicação das terminologias, ficando-se por uma Revolta produzida por revoltosos. A Comuna de Paris de 1871 como tema de debate 
parlamentar, verificar-se-ia por intermédio de uma publicação, na imprensa académica, por parte de José Falcão, que glorificava os feitos da mesma. Assim, se propiciou um debate envolto em censuras.

\section{Referências}

ALVES, Ana Maria. Portugal e a Comuna de Paris. Lisboa: Editorial Estampa, 1971.

ARENDT, Hannah. Sobre a Revolução. Lisboa: Moraes Editores, 1971.

BANDEIRA, Luiz Alberto Moniz. Fórmula para o caos - A CIA e o outro 11 de Setembro: a queda de Salvador Allende (1970-1973). Lisboa: Tribuna da História, 2009.

CÂMARA DOS DEPUTADOS, Diário da Câmara dos Senhores Deputados da Nação Portugueza, Disponível em: http://debates.parlamento.pt/catalogo/mc/cd, em 15-012014.

CHAGAS, Manuel Pinheiro. História da revolução da Comuna de Paris. Lisboa: José Augusto Vieira Pare, 1871.

DUSO, Giuseppe. Revolução e constituição do poder. In DUSO, Giuseppe (org.). $O$ Poder: História da Filosofia Política Moderna. Petrópolis: Editora Vozes, 2005.

ETIMOLOGIA DE “REVOLUÇÂO”, Disponível em: http://www.gramatica.net.br/ origem-das-palavras/etimologia-de-revolucao/, em 17/01/2014.

FERREIRA, Fátima Sá e Melo. O conceito de revolução na História dos Conceitos: um percurso em Portugal, 1750-1879. In: PEREIRA, Miriam Halpern (org.). Linguagens e fronteiras do poder. Lisboa: Centro de Estudos de História Contemporânea. Instituto Universitário de Lisboa, 2012.

GASPAR, Carlos "Revolução", Dicionário de Filosofia Moral e Política. Disponível em:http://www.ifl.pt/private/admin/ficheiros/uploads/246147678e66dbfbec6c31000a09 e989.pdf, em 28/12/2013.

LARA, António de Sousa. Ciência Política: estudo da ordem e da subversão. Lisboa: Instituto Superior de Ciência Sociais e Políticas, 2007.

LÉNINE, Vladimir Ilitch. A Comuna de Paris. Lisboa: Edições Avante, 1975.

MALAPARTE, Cúrzio (1984). Técnica do Golpe de Estado. Mem Martins: Publicações Europa-América.

MICHEL, Louise. A Comuna. Lisboa: Editorial Presença, 1971. 
TILLY, Charles. As Revoluções Europeias 1492-1992. Lisboa: Editorial Presença, 1996.

VILAÇA, Alberto de Oliveira. A Comuna de Paris e a $1^{a}$ Internacional revisitadas em Portugal. Porto: Campo das Letras, 2005. 